\title{
Watchdog Journalism during the Coronavirus Crisis in Turkey
}

\author{
Ayşe Fulya Şen \\ Faculty of Communication, Firat University, Elazığ, Turkey \\ Email: fulyasen@firat.edu.tr
}

How to cite this paper: Şen, A. F. (2021). Watchdog Journalism during the Coronavirus Crisis in Turkey. Advances in Applied Sociology, 11, 500-512.

https://doi.org/10.4236/aasoci.2021.1110044

Received: September 15, 2021

Accepted: October 25, 2021

Published: October 28, 2021

Copyright () 2021 by author(s) and Scientific Research Publishing Inc. This work is licensed under the Creative Commons Attribution International License (CC BY 4.0).

http://creativecommons.org/licenses/by/4.0/

\begin{abstract}
This study aims to question the watchdog function of the Turkish press in the context of the coronavirus crisis, to deal with the initial coronavirus responses of the news media, and to examine the extent to which the press fulfills its public responsibility and watchdog function. Accordingly, it discussed the role of the media in protecting the public interest in terms of watchdog journalism and centered on the matter of how the news media debate social welfare measures taken for the fragile social groups during the coronaviruses crisis. The study claims that pro-government media present a health-based perspective, but anti-government media much more point out the socio-economic dimensions of COVID-19. The online newspapers that are selected according to the range of different political stances, in particular, anti-government and pro-government, have been investigated through content analysis in terms of content diversity and watchdog journalism. Thus, it has been determined whether watchdog journalism is fulfilled in such a polarized political environment in the context of news on COVID-19 and concluded that the news media ignore social policy measures, are polarized along political lines, and are not critical enough of the government.
\end{abstract}

\section{Keywords}

Watchdog Journalism, Accountable Journalism, Social Responsibility, Coronavirus Crisis, Liberal-Pluralist Approach

\section{Introduction}

Media generate a great deal of popular interest and debate, specifically regarding controversial topics. A sociological perspective provides a set of tools to comprehend media-related issues and the role of media in the context of the economy, politics, and so forth. To understand the media and their impact on society, we must consider the relationships between the media and the social world. Seeing 
the relationships between institutions such as the media industry and government on a different level is also important to recognize the controversial roles of the media. The liberal-pluralist perspective defends a free-market approach for the public interest, but in reality, the debate is far more complicated and reflects competing interests. The intended target of media regulation differs based on political orientation. On the other hand, commercialization makes it difficult to maintain a critical voice (Croteau \& Hoynes, 2014). Within liberal democracies, the news media is an integral part of politics. Furthermore, the news is a public good produced by professional journalists working for the private sector news media operating for profit; therefore, it is also a part of the marketplace. Because of the long-term structural decline of newspapers, the digital media has accelerated and had dramatic implications for business sustaining journalism. The digital media's environment is defined increasingly algorithmically, which helps users discover content, on the other hand, it also creates information inequalities (Nielsen \& Fletcher, 2020). The intertwined relationships between media moguls and governments lead to extinguishing critical viewpoints to governments and diminishing varieties in news content. Therefore, it is crucial to construct an independent media from capital and government.

Watchdog journalism is acknowledged as one of the most important contributions of the press to democratic life and identified with reporting that denounces wrongdoing in government and the private sector. It reflects the interests of various organizations to make democracy more transparent and powerful actors accountable to citizens (Waisbord, 2016). At this point, it is necessary to think about what kind of journalism matters. One of them is "accountability journalism". It is a journalism of original reporting, presented in an emotionally compelling way, and it makes a democratic government more fully accountable to the public. Democracy cannot truly exist if accountability journalism does not. Journalism holds government officials and government agencies, sometimes holds other sources of power accountable to the public for their actions (Schudson, 2020). This kind of journalism brings new insights and solutions to the public sphere.

The public sphere metaphor cites structured power relations. In its specific detail, it is defined by the prevailing political order, economic relations, cultural repertoires, and the affordances of technologies. The analytical task is to understand how these interconnect and work. The normative question is whether an open communicative space is a crucial collective good necessary to democratic politics. In this sense, the reappraisal of the media ecology stems from a concern with managing information about COVID-19 is a moot point (Schlesinger, 2020).

As Schudson (2020: p. 3) also notes, “The world will survive without a lot of the journalism we have today, but the absence of some kinds of journalism would be devastating to the prospects for building a good society, notably a good democratic political system". Therefore, it is important to question the ways to hold governments accountable, the norms and practices of professional journalism 
and to discuss why we should care about them. While the coronavirus pandemic continues to raise concerns for the public, the crisis also raises a number of questions for journalism research. This study draws attention to the importance of well-reported, compelling, and assertive journalism (inspired by Schudson, 2020), and attempts to analyze COVID-19 related matters most reported, compelling, and assertive.

This study deals with the initial coronavirus responses of the news media in Turkey and examines the extent to which the press fulfills its public responsibility and watchdog role. In this study, I discussed the role of media in protecting the public interest in terms of watchdog journalism and centered on the matter of how the news media debate social welfare measures taken for the fragile social groups during the coronaviruses crisis. I also claimed while pro-government media present a health-based perspective, anti-government media much more point out the socio-economic dimensions of COVID-19. In order to analyze the diversity of journalistic viewpoints on the coronavirus crisis, I focused on how the newspaper websites had covered coronavirus-based problems. I argued that the media regime in Turkey prevents the media to fulfill social responsibility and advocating public interest. To discuss the media's responsibility towards the public, I raised these questions:

- Which social groups' needs have been firstly covered on the news media with the outbreak of the coronavirus crisis?

- How did the news media evaluate the strategies of the government to combat the pandemic?

- What are the main themes of the news about the coronavirus crisis?

- How does polarization in politics determine the news frames about the pandemic in Turkey's case?

- Do the news media treat the matter only as a health issue, or else point out the different dimensions of the coronavirus crisis as well?

- What are the differences in themes of the news about the coronavirus crisis?

The COVID-19 pandemic is a global issue needing to be tackled with health and social policies at the same time; hence governments are primarily charged to minimize risks and maintain society's health. At this point, the news media should monitor how the government manages this global crisis and what kinds of measures it takes to prevent the economic and social problems of vulnerable social groups. Watchdog journalism is an important mechanism to maintain the public interest in democratic systems. This study aims to question the watchdog function of the press and the politics of journalism in the context of the coronavirus crisis. For this purpose, I made a content analysis of online newspapers by considering diversity and watchdog journalism and selected these platforms according to the different political stances, in particular anti-government and pro-government. Thus, I revealed whether watchdog journalism is fulfilled in such a polarized political environment in the context of news on COVID-19. The analysis covers a total of 856 news stories in a one-month period from 10th March-10th April 2020, on which the first coronaviruses cases appeared in Tur- 
key.

\section{Theoretical Framework}

The liberal-pluralist approach sees the press as the "fourth estate" playing an important part in the democratic process in constituting a source of information that is independent of the government. The concept of "fourth estate" means to the free and open circulation of ideas (Bennett, 1982). Norris (2014) discusses whether the news media actually serve as watchdogs of the public interest and points out that journalists often face serious economic, technological, and political constraints in fulfilling these ideals. Liberal theorists have long advocated the notion of watchdog journalism. Accordingly, it is claimed that political information provided by independent media helps citizens evaluate the performance of their elected leaders, both individually and collectively.

One of the main criteria of journalism is "public interest" meaning certain benefits to society. The media carry out a number of important, even essential, tasks in contemporary society and it is in the general interest that these are performed well. The idea of public interest involves positive expectations. The media contents are influenced by the political, cultural and economic determinants. However, in the practice of media politics, law and regulation, there seems to have been quite a lot of agreement on the main components of the public interest in respect of mass media. Notably, diversity of information, opinion and culture, high quality of information and culture, and supporting of the democratic political system are the main normative expectations relating to the structure and content of media in western-type democracies. Media should reflect in their structure and content the various social, economic and cultural realities of the societies (and communities) in which they operate. While more media channels also seem to promise more diversity, the quality of that diversity is far from assured due to its ownership structure (McQuail \& Deuze, 2020). In the relationship between journalism and democracy, reliance on the market is seen as the way of keeping from the government and the "free market mythology" come under sustained scrutiny (Josephi, 2012). Curran (1991) notes the free-market approach limits the ideological and cultural diversity of the media. A basic requirement of democratic media is to represent all different interests in society.

It exists a vast literature that acknowledges the importance of the politics-media relationship. Many attempts to make sense of the relationship between politics and media deal with the different aspects of that relationship. Street (2011: p. 10) sees this as a power relationship and points out two dimensions to this: The power over media and the power of the media. In respect of the first dimension, media does not simply mirror reality, imposes particular stories upon the world. Hence, it should look to those with a direct interest in the outcome, those with most to gain such as the governments, parties, and politicians. The second dimension is the impact the media have on the world they report. The relationship between politics and mass media is related to patterns of control that or- 
ganize media and the institutional interests that shape the change. Streeter (1989: p. 88) points out the paradox of the mainstream approach. This apparent paradox reflects a set of chronic confusions in contemporary media studies surrounding the plurality of its meaning. The difference between mainstream research and the critical and cultural alternatives is that one side in the debate acknowledges plurality and the other reduces it, or that one side ignores the exercise of power while the other uncovers it. The most important role of the news media is to contribute to the public sphere.

Critical approaches argue that media, like other cultural institutions in a class society, produce ideology and represent the interests of an elite minority to the subordinate majority (McNair, 1999). Marxist-based perspective examines the media industries and their practices of production, draws attention to the economic, corporate, governmental structures and tries to figure out how the mass media operates. Moreover, media messages, ideologies, and media representations of different social identities are the main issues of cultural perspective (Ott \& Mack, 2010). It should be questioned who owns the media. As media ownership concentrates in fewer and fewer hands and media companies become part of much larger corporations, this concentration creates homogeneity in media content. Another consequence is to determine the political agenda. Media empires promote a specific political viewpoint. While this view has become "our" view, the interests of corporate entities are represented as universal values (Croteau \& Hoynes, 2014). Allan (2004: p. 80) points out that news discourse conceals or masks the true origins of economic antagonisms.

The political economy perspective is a key to understand the nature of news. The concentration of media ownership has led to narrowing heard voices in a media setting. The narrowing of the media's public sphere role stems from a concentration and conglomeration of the media. The structure of media ownership makes it difficult to sustain the media as an objective public sphere because while the primary task of the public sphere is to criticize government policies, the public sphere is controlled by the dominant discourse (Devereux, 2014). Garnham (2012, pp. 171-174) offers a new perspective on the relationship between the economic and ideological dimensions of media. Mass media are ideological tools of ruling-class domination either through direct ownership or, via ruling-class control of the State. One of the key features of the mass media within monopoly capitalism is political and ideological domination through economic power.

The economic organization of news is based on the relationship between the state, market, and society. Economic perspective has been insensitive to political and legal determinants of news production. The government directly runs public broadcasting. Within market societies, there are various political forms and constitutional regimes for the press. Different variations create a distinct politics of media. There is a serious ideological contestation in liberal democracies and just how it takes place differs depending on the political institutions (Schudson, 2019). Neoliberal logics are articulated with media as logics 
of market determinism, commodification, individualization, competitive ritual, and self-interest. Economic arguments are rhetorically and affirmatively styled as pragmatically "realistic," a form of realism that obscures its rhetoricity. Ideas of ideology and rhetoric are signified as the enemies of journalistic truth. This normative vision of journalism privileges a logic of unity and consensus over division and conflict, and is embedded within a conventional, pluralist idea of liberal democracy, one that is grounded in a faith in the utility of registering the arguments and considering the "facts." Journalistic ideas of the "common good" and the "national interest" have internalized the logic of market determinism (Phelan, 2014).

In this context, neoliberalism has produced a structural transformation in media industries. Neoliberalism is connected to deregulation and the increased penetration of market logic, so it impacts the structures of mass media. Specifically, since the 1980s the media has become a key site of ideological struggle to win public consent for neoliberal policies. Media deregulation has brought the value of the free market to the forefront. Hence, the media is the site of ideological struggle for legitimating and strengthening neoliberalism (Berry, 2019). Both ownership of media and cultural dimensions of social structure have influence in homogenizing of media contents. In addition, political institutions and conflicts determine the process of news production and news making. Hanitzsch et al., (2011: p. 275) evaluate journalistic culture as connected to interventionism, power distance, market orientation, objectivism, empiricism, and ethical ideologies. Hence, journalism culture materializes in terms of the professional values journalists embrace.

\section{Method}

Content analysis is directed toward the objective features of texts, uses some coding procedure, and attempts to build an understanding of the meaning of the content by a thorough description of its component properties and starts by getting the facts of the text (Anderson, 2012). This study is based on the coding of online news content that is appropriate for answering particular research questions and it involves the frequency counts, theme, and keyword analysis. To describe the characteristics of the news stories, units of sampling have been compared to each other. I collected 856 news articles published in one-month period between 10th March-10th April 2020 on which is the first coronaviruses cases appeared in Turkey and coded the contents to identify differences.

This study is based on qualitative web content analysis focusing generally more on the latent content than the quantitative content analysis. The latent content refers to what the text meant. Latent content analysis involves the application of coding schemes and the use of statistical techniques to establish whether website keywords were structured in particular discourses about anything (Ackland, 2013). In order to distinguish the facts of the online news content, I selected sampling units representing different political tendencies and categorized the news web- 
sites on the basis of being anti/pro-government. Hence, I aimed to understand which factors much more determine the news framework in the Turkish media landscape among watchdog journalistic routines, social responsibility consciousness, partisanship, or political parallelism. I used Schudson's (2020) classification of news to identify the critical viewpoint of news.

Schudson (2020, pp. 36-42) points that journalism is an effort to relate to a public what political leaders have done, what they are doing, and what they intend to do and defines criteria characterizing journalism that holds the powerful accountable to the public and to the institutions of democracy. These criteria are as follows: "Reported", "compelling", and "assertive". "Reported" means doing the reporting to get the relevant facts and to get them right. "Compelling" is related to storytelling and "personification" which enables audiences to become emotionally engaged by them and it aims "to move people". "Assertive" is refers to investigative and analytical reporting. It is an effort to investigate a topic that does not specifically respond to a breaking news event, then that is more obviously an intervention in the public agenda rather than an exploration of an established public agenda. It also includes analysis to make a current debate or disagreement meaningful to the audience and to be understood.

To reach these findings and provide diversity in sampling units; I analyzed the news of right wings and pro-government, center-left, and radical-left news websites, classified news of COVID-19 through keywords of "covid," "coronavirus," or "corona". After that, I interpreted the meaning of news whether it mirrors the watchdog perspective through certain themes.

\section{Findings and Analysis}

The idea that journalism should reflect different interests and values in society, and provide access to the widest possible range of voices is broadly shared among journalists, researchers, and other media critics. However, this liberal functionalist understanding of pluralism has been widely criticized for ignoring real, structural inequalities between social groups in terms of their access to the media and the public sphere (Karppinen, 2018).

News coverage influences public views and plays a critical role in shaping public opinion around emerging science and risk issues and amplifies value and belief differences on the issue (Hart et al., 2020). This study shows how social responsibility and the watchdog role was ignored in journalistic routines by analyzing early news coverage of COVID-19 according to Schudson's (2020) news categorization (see Table 1).

Mostly, the news sites have conveyed the information on the coronavirus crisis by a "reported news" form. Except for a few compelling and critical reporting, there is no newsgathering effort questioning the underlying reasons for the issues. Sabah has mostly reported the developments on COVID-19 from an informative and neutral tone and with reference to the political actors and medical 
Table 1. The tone of the news ( $10^{\text {th }}$ March-10 $10^{\text {th }}$ April 2020).

\begin{tabular}{cccc}
\hline & Reported & Compelling & Assertive \\
\hline Sabah & 161 & 8 & - \\
Habertürk & 133 & 12 & - \\
Hürriyet & 203 & 27 & - \\
Cumhuriyet & 51 & 4 & 10 \\
Birgün & 177 & 70 & 10 \\
Total & 725 & 121 & \\
\hline
\end{tabular}

experts. Furthermore, some news stories can be depicted as "compelling" in terms of relevance and being interesting and are based on personal stories on defeating COVID-19 disease. Habertürk has heavily contained "reported" news and its small part of coverage has the features of compelling. This news is related to persons recovering or dying from COVID-19 and important enough to run on a web page. Hürriyet has also mostly framed the coronavirus news by "reported" style. However, the personal stories on the discharging from hospital or death have been reported by a "compelling" style to draw attention to public and to take a measure towards coronavirus.

Reported news refers to the relevant facts and to get them right and means being able to assess the reliability of evidence. It also puts the facts together. Reported news refers to the relevant facts and to get them right and means being able to assess the reliability of evidence. It also puts the facts together. "Reported news" is the basis of writing a story that is compelling (Schudson, 2020). In this study, it is seen that the news within the reported category rarely goes beyond the gathering of information because of gathering from the state sources. Hence, Cumhuriyet has also produced more "reported news" than others. Furthermore, there is no "assertive news" based on investigative reporting in Cumhuriyet, except for a few "compelling news". Although Birgün has given wide coverage to the "reported news", like other newspapers, it has framed the news that points out social policies with a tone of more aggressive to display its importance. Birgün has critically reported on workers losing their jobs, health care system and local businesses being at risk of closing permanently and highlighted the inequities that threaten people's well-being, safety, and lives by "compelling" and "assertive" news.

At the second level of the content analysis, I focused on the themes of the news stories and aimed at revealing the perspective of the news coverage in terms of health-based or social policy-based frames (see Table 2).

Firstly, while the themes on the health system and hospitals, numbers of COVID-19 cases, and deaths have been more covered than others, the theme of social policy responses to the COVID-19 crisis and protecting workers' rights 
Table 2. Main themes of news coverage.

\begin{tabular}{|c|c|c|c|c|}
\hline $\begin{array}{l}\text { Main themes of } \\
\text { coronavirus news } \\
\text { coverage }\end{array}$ & $\begin{array}{l}\text { Social policy responses to } \\
\text { the COVID-19 crisis and } \\
\text { protecting workers' rights }\end{array}$ & $\begin{array}{l}\text { Lockdown } \\
\text { measures }\end{array}$ & $\begin{array}{l}\text { Health system and hospitals, } \\
\text { numbers of COVID-19 } \\
\text { cases and deaths }\end{array}$ & $\begin{array}{c}\text { Face mask, protective equipment, } \\
\text { disinfectant, quarantine, hygiene } \\
\text { measures }\end{array}$ \\
\hline Sabah & 15 & 47 & 66 & 41 \\
\hline Habertürk & 7 & 24 & 81 & 33 \\
\hline Hürriyet & 43 & 52 & 72 & 63 \\
\hline Cumhuriyet & 10 & 11 & 17 & 17 \\
\hline Birgün & 59 & 17 & 100 & 81 \\
\hline Total & 134 & 151 & 336 & 235 \\
\hline
\end{tabular}

have been less covered and debated. These findings illustrate the news media have framed the COVID-19 crisis from the perspective of medical and health news than a public health issue having economical and social aspects. Sabah has reported the news stories themed social aid campaign, financial support, and employment rights along a pro-government partisan perspective and also highlighted powerful the healthcare system of Turkey. This kind of news coverage means being in line with political elites they trust and rejecting information not aligned with this view, even if the information comes from experts (Hart et al., 2020). Similarly, Habertürk has reported the coronavirus matter from healthbased perspective and mostly focused on the statements of the experts'. On the other hand, it has not framed enough the socio-economic consequences and employees' work-based issues and conveyed the government's economic and administrative policies towards reducing impacts of coronavirus crisis. The news coverage of Habertürk is on staying healthy and preventing the spread of COVID19. Looking at news coverage of Hürriyet, it is seen that Hürriyet has more focused on the latest coronavirus developments and the scientific researches on prevention and treatment the coronavirus, the numbers of confirmed cases. On the other hand, the news coverage of economic policy and labor market measures has been relatively underrepresented to other themes and the business subsidies have been more represented rather than fiscal supports for employees.

Cumhuriyet, like other mainstream newspapers, has focused on the information about coronavirus-based cases and steps taken to protect. But, it has a lower of news coverage of the social and economic impact of the coronavirus crisis than the medical news. Birgün has pointed out the impacts of lockdowns and quarantines on the economic conditions of vulnerable communities and dealt with COVID-19 as a political phenomenon. Therefore, it has evaluated the implementation of curfews, quarantines, and stay-at-home orders in terms of social welfare rights. Birgün has not only drawn attention to combatting to the spreading of pandemic but also focused on devastating impacts of neoliberal policies on the working class during early stage of pandemic. Furthermore, it has also highlighted the importance of transparency about the number of COVID-19 cases admitted to the hospitals. 


\section{Conclusion}

Watchdog journalism necessities working for the public interest, spreading the information the public needs, and strengthening accountability in a democratic society. Watchdog journalism is important to provide attributing responsibility and assigning praise or blame for certain outcomes. An increasingly severe challenge to watchdog journalism stems from the contemporary economic pressures that mainstream news media facing. Watchdog journalism asks hard questions of the powerful, aims to maximize transparency, and serves the public interest. Many conditions such as the lack of freedom of expression and commercial pressures limit watchdog journalism. In its stronger version, journalists are the key actors uncovering the abuse of power and thereby triggering public outrage and legal actions. In the weaker or more routine version, journalists are secondary actors reporting the outcome of other accountability bodies and bringing these matters to public attention. It is most pervasive in Anglo-American democracies, but in other countries, the more critical role for the independent news media seems to have developed with the processes of democratization (Norris, 2014). Quality media, unlike popular media, should provide the information required for policy making plus analysis and debate of policy issues (Louw, 2010: p. 43). News is central to how people understand the coronavirus crisis and evaluate the government's response to it. People's judgments on government response are shaped by news media (Nielsen, Kalogeropoulos, \& Fletcher, 2020). Giroux (2020) argues that the pandemic is more than a medical concept and it also refers to ideological and political plagues that emerged as a result of the irresponsible response of countries to the COVID-19 crisis.

This study has dealt with how central news organizations help people stay informed and the public policy responses of the news during the pandemic. In Turkey, it can be observed that independent and left-wing news media practice watchdog journalism and criticize political power to develop and keep democracy. This study shows that polarization and political advocacy determine the news framework. The critical news perspective highlights economic and political forces prioritize profits over human needs and pandemic policies have been taken place in favor of capital owners. A thematic review of articles has demonstrated that published news on coronavirus in mainstream media seems like health news based on state-backed sources. Also, I found that left-wing and opponent media towards the government generally politicize health news by criticizing the AKP government as incompetent. This study displays that most mainstream news coverage consists of junk news and politicizes health news and information by praising the AKP government. In general, pro-government and center-right media include junk and routine news articles on the coronavirus crisis by ignoring many structural issues. A substantial number of articles simply report the administrative measures protecting people from coronavirus and also ignored the substantive content of the economical issues related to welfare rights.

As also Norris (2014) notes, many conditions limit watchdog journalism, in- 
cluding those arising from lack of freedom of expression, commercial pressures from private owners and advertisers. In Turkey, power relations within the realm of mass media and the formation of mainstream conservative media have discouraged independent investigative journalism. To sum up, ideology plays a role in the media's assessments of the national coronavirus response and those on the political left are more critical. It has been seen that news media act as the role of politically motivating. It can be concluded that the news media have ignored social security measures. When we look at how news media evaluate the contents of social benefit payments for vulnerable social groups during the lockdown and whether they question social inequalities, we see that news coverage is polarized along political lines and the mainstream news media have not been critical enough of the government.

Investigative journalism is noticed by politicians, corporations, and other elite audiences because it has an impact that demands a response. This mission is integral to the culture of journalism (Birnbauer, 2019). Despite its significance, media corporations due to many constrained factors such as commercial profit, political oppression, and self-censorship ignore watchdog journalism. Watchdog or investigative journalism is one of the basic principles of a democratic society to provide insight into society and politics. In an era of tabloid media, it is seen that celebrity, crime, and sports news or superficial news, which disregards the context of the economic and political, is more at the forefront than watchdog journalism.

To maintain journalism, watchdog journalism should be revived and turned back to conventional codes of journalism.

\section{Conflicts of Interest}

The author declares no conflicts of interest regarding the publication of this paper.

\section{References}

Ackland, R. (2013). Web Social Science. Sage.

Allan, S. (2004). News Culture (2nd ed.). Open University Press.

Anderson, J. A. (2012). Media Research Methods: Understanding Metric and Interpretive Approaches. Sage.

Bennett, T. (1982). Theories of the Media, Theories of Society. In M. Gurevitch, T. Bennett, J. Curran, \& J. Woollacott (Eds.), Culture, Society and the Media (pp. 26-51). Methuen \& Co. Ltd.

Berry, M. (2019). Media and Neo-Liberalism. In J. Curran, \& D. Hesmondhalgh (Eds.), Media and Society (pp. 57-82). Bloomsbury.

Birnbauer, B. (2019, September 23). Investigative Journalism: Demystifying Some of Its Practices, Beliefs and Challenges.

https://lens.monash.edu/@politics-society/2019/09/23/1376732/investigative-journalis

m-demystifying-some-of-its-practices-beliefs-and-challenges

Croteau, D., \& Hoynes, W. (2014). Media/Society: Industries, Images, and Audiences. 
Sage.

Curran, J. (1991). Rethinking the Media as a Public Sphere. In P. Dahlgren, \& C. Sparks (Eds.), Communication and Citizenship (pp. 27-57). Routledge.

https://doi.org/10.4324/9780203977880-1

Devereux, E. (2014). Understanding the Media. Sage.

Garnham, N. (2012). Contribution to a Political Economy of Mass-Communication. In M. G. Durham, \& D. M. Kellner (Eds.), Media and Cultural Studies: Key Works (pp. 166-185). Wiley-Blackwell.

Giroux, H. (2020, October 22). Fascist Culture, Critical Pedagogy, and Resistance in Dark Times.

https://www.counterpunch.org/2020/10/22/fascist-culture-critical-pedagogy-and-resist ance-in-dark-times/

Hanitzsch, T., Hanusch, F., Mellado, C., Anikina, M., Berganza, R., Cangoz, I., Coman, M., Hamada, B., Hernández, M. E., Karadjov, C. D., Moreira, S. V., Mwesige, P. G., Plaisance, P. L., Reich, Z., Seethaler, J., Skewes, E. A., Noor, D. V., \& Wang, Y. E. K. (2011). Mapping Journalism Cultures across Nations. Journalism Studies, 12, 273-293. https://doi.org/10.1080/1461670X.2010.512502

Hart, P. S., Chinn, S., \& Soroka, S. (2020). Politicization and Polarization in COVID-19 News Coverage. Science Communication, 42, 679-697. https://doi.org/10.1177\%2F1075547020950735

Josephi, B. (2012). How Much Democracy Does Journalism Need? Journalism, 14, 474-489. https://doi.org/10.1177\%2F1464884912464172

Karppinen, K. (2018). Journalism, Pluralism, and Diversity. In T. P. Vos (Ed.), Journalism (pp. 493-510). De Gruyter Mouton. https://doi.org/10.1515/9781501500084-025

Louw, P. E. (2010). The Media and Political Process. Sage.

McNair, B. (1999). News and Journalism in the UK(3rd ed.). Routledge.

McQuail, D. and Deuze, M. (2020). Mcquail's Media \& Mass Communication Theory (7th ed.). Sage.

Nielsen, R. K., \& Fletcher, R. (2020). Democratic Creative Destruction? The Effect of Changing Media Landscape on Democracy. In N. Persily, \& J. Tucker (Eds.), Social Media and Democracy: The State of the Field, Prospects for Reform (SSRC Anxieties of Democracy) (pp. 139-162). Cambridge University Press. https://doi.org/10.1017/9781108890960

Nielsen, R. K., Kalogeropoulos, A., \& Fletcher, R. (2020, May 5). UK Public Opinion Polarised on News Coverage of Government Coronavirus Response and Concern over Misinformation.

https://reutersinstitute.politics.ox.ac.uk/UK-public-opinion-polarised-on-news-covera ge-government-coronavirus-response-concern-over-misinformation

Norris, P. (2014). Watchdog Journalism. In M. Bovens, R. E. Goodin, \& T. Schillemans (Eds.), Oxford Handbook of Public Accountability (pp. 525-541). Oxford University Press.

Ott, B. L. \& Mack, R. L. (2010). Critical Media Studies: An Introduction. Wiley-Blackwell.

Phelan, S. (2014). Neoliberalism, Media and the Political. Palgrave Macmillan. https://doi.org/10.1057/9781137308368

Schlesinger, P. (2020). After the Post-Public Sphere. Media, Culture \& Society, 42, 1545-1563. https://doi.org/10.1177\%2F0163443720948003

Schudson, M. (2019). Approaches to the Sociology of News. In J. Curran, \& D. Hesmondhalgh (Eds.), Media and Society (pp. 139-166). Bloomsbury. 
https://doi.org/10.5040/9781501340765.ch-008

Schudson, M. (2020). Journalism: Why It Matters. Polity Press.

Street, J. (2011). Mass Media, Politics \& Democracy. Palgrave.

Streeter, T. (1989). Polysemy, Plurality, and Media Studies. Journal of Communication Inquiry, 13, 88-106. https://doi.org/10.1177\%2F019685998901300210

Waisbord, S. (2016). Watchdog Journalism. In G. Mazzoleni (Ed.), The International Encyclopedia of Political Communication (pp. 1-5). John Wiley \& Sons, Inc. https://doi.org/10.1002/9781118541555.wbiepc046 